\title{
Receptor Kinase AXL is Modulated in the Osteogenic Differentiation of Human Mesenchymal Stromal Cells on Modified Titanium Implant Surfaces
}

\author{
Mohammad Ramine Khan', Nikolaos Donos ${ }^{2,3}$, Vehid Salih ${ }^{2,4}$ and Peter Mark Brett ${ }^{2 *}$ \\ ${ }^{1}$ Veterinary Clinical Sciences, The Royal Veterinary College, UK \\ ${ }^{2}$ Biomaterials and Tissue Engineering, UCL, Eastman Dental Institute, University College London, UK \\ ${ }^{3}$ Department of Periodontology, UCL, Eastman Dental Institute, University College London, UK \\ ${ }^{4}$ Plymouth Dental School, Peninsula Schools of Medicine and Dentistry, Drakes Circus, Plymouth University, UK
}

\begin{abstract}
Titanium (Ti) implants with micro-rough topography and high surface free energy promote osseointegration, which in vitro analyses suggest is due to a novel enhancement in cellular osteogenic differentiation and function. The AXL receptor tyrosine kinase (AXL) is expressed on mesenchymal stromal cells (MSCs) and is implicated with its ligand, Growth arrest-specific 6 (GAS6), in the negative regulation of osteogenic differentiation, and may be modulated in the enhanced osteogenic differentiation of MSCs on modified Ti surfaces. This hypothesis was tested by culturing human MSCs on tissue culture plastic (TCP), polished (P), micro-rough-hydrophobic (SLA) and micro-rough hydrophilic (modSLA) Ti surfaces for seven days. Total RNA and protein levels of AXL and GAS6 were examined by real time PCR and ELISA, respectively. The effects of deregulating the signalling pathway in hMSCs with either receptor agonist or antagonist were investigated by analysing calcium mineralisation and soluble osteoblastic marker synthesis. The MSCs were found to significantly down-regulate AXL and GAS6 earlier on rough surfaces compared to smooth over seven days. Addition of the receptor agonist caused a relative decrease in calcium mineralisation that was most marked for TCP compared to any Ti surface. The antagonist did not affect mineralisation but caused a relative increase in osteoblastic soluble protein levels on rough surfaces only. Gene expression data showed an up-regulation of RUNX2 and beta-catenin with the receptor antagonist. These findings suggest that a down-regulation of $A X L$ correlates with increased cellular mineralisation on the modified surfaces and that it might be a putative biomarker for assessing the clinical efficacy of endosseous implants.
\end{abstract}

Keywords: AXL; GAS6; Mesenchymal stromal cells; Adult stem cell; Osteogenesis; Titanium implants

\section{Introduction}

Titanium ( $\mathrm{Ti}$ ) is a biocompatible highly reactive metal with a stable surface oxide layer that permits the deposition of cellular components aiding successful integration of endosseous implants [1]. Modifying the surface properties of an implant can enhance osseointegration in the early stages of healing [2]. The clinically beneficial effect of a modified Ti implant surface (sand blasted acid-etched micro-rough hydrophobic surface (SLA)) on osseointegration has been widely demonstrated with evidence showing a significant promotion in early healing parameters such as peri-implant new bone formation and bone-implant contact percentages, compared with relatively smooth surfaces [2]. These observations were further supported by in vitro findings demonstrating distinct differences in the activity of committed osteoblastic cells on rough compared to smooth Ti implant surfaces [3-5]. Interestingly, the quantitative parameters to assess osseointegration have been shown to be further promoted by modifying surface free energy of the hydrophobic SLA to render it hydrophilic [6,7]. This modified (modSLA) surface seems to have an enhanced effect that significantly reduces the healing period compared to SLA. This was demonstrated by higher clinical implant attachment scores [8] as well as significantly higher neo peri implant bone formation and bone-implant contact, as early as two weeks post implantation $[9,10]$. Clinical examinations have also demonstrated modSLA to be capable of retaining bone debris [11] that may contribute to an earlier transcriptional up-regulation of important osteogenic markers in vivo compared to the hydrophobic SLA substrate, as early as 2 days post implantation in human subjects [12-14].

It has been suggested that the mechanism underlying the improved osseointegration of modified Ti surfaces is an enhancement in cellular differentiation and function instigated in response to physical cues from micro-rough topographies [15-17]. This hypothesis is supported by studies examining the effects of modified Ti surfaces on multipotent human mesenchymal stromal cells (MSCs). MSCs have been implicated in tissue repair and regeneration in vivo [18] and can differentiate into at least three mesenchymal phenotypes (chondrogenic, adipogenic and osteogenic), suiting them for in vitro modelling of tissue repair and healing. Further it has been shown that MSCs exhibit different levels of calcium mineralisation in vitro dependant on the Ti substrate used $[15,17]$, seemingly under the influence of selectively stimulated molecular pathways $[19,20]$.

AXL is a cell surface receptor expressed on MSCs [21] that dimerises in the presence of its natural ligand GAS6 to initiate a range of cellular functions, including survival, inflammation and differentiation [22]. Previously microarray analyses have shown that

${ }^{*}$ Corresponding author: Dr Peter Mark Brett, Biomaterials and Tissue Engineering UCL, Eastman Dental Institute, University College London, 256 Grays's Inn Road, London WC1X 8LD, United Kingdom, Tel: 0044 (0)203 456 1104; Fax: 0044 (0)203 456 1104; E-mail: p.brett@ucl.ac.uk

Received August 07, 2014; Accepted September 12, 2014; Published September 14,2014

Citation: Khan MR, Donos N, Salih V, Brett PM (2014) Receptor Kinase AXL is Modulated in the Osteogenic Differentiation of Human Mesenchymal Stromal Cells on Modified Titanium Implant Surfaces. J Stem Cell Res Ther 4: 233. doi:10.4172/2157-7633.1000233

Copyright: @ 2014 Khan MR, et al. This is an open-access article distributed unde the terms of the Creative Commons Attribution License, which permits unrestricted use, distribution, and reproduction in any medium, provided the original author and source are credited. 
AXL is transcriptionally up-regulated in human alveolar bone cells very soon after contact with rough Ti surfaces [5]. AXL was simultaneously shown to undergo down-regulation prior to osteogenic mineralisation in bovine MSC like cells called pericytes in vitro $[23,24]$ as well as in the progression of chondrogenenic differentiation of human MSCs [25]. Restoration of AXL/GAS6 signalling has also been associated with the inhibition of ectopic endothelial cell calcification in vivo through statins [26]. The function of the Twist transcription factors, which are downstream effectors of this pathway, strongly suggests that the pathway is a potent negative regulator of osteogenic differentiation [27]. These characteristics of AXL suggest that it might be a suitable biomarker for the evaluation of the effectiveness of novel implant surface designs and materials for osseointegration.

The present study hypothesised that AXL and GAS6 are differentially modulated resulting in the enhanced osteogenic responses of MSCs to modified Ti implant surfaces in vitro. This hypothesis was examined in human MSCs cultured on tissue culture plastic (TCP), polished Ti (P), rough-hydrophobic (SLA) and rough-hydrophilic (modSLA) Ti discs in osteogenic medium $(\mathrm{OM})$ alone or OM supplemented with either agonist or antagonist of the AXL receptor. The effects of deregulating receptor signalling on MSCs were assessed by quantifying extracellular matrix calcium and collagen content, soluble Osteoprotegrin (OPG) and Growth Differentiation Factor type 15 (GDF-15) levels in culture supernatant.

\section{Materials and Methods}

\section{Modified Ti surfaces}

The Ti discs were supplied by Institut Straumann AG (Walderberg, Switzerland). Three modified Ti implant surfaces were investigated in this study: a polished $(\mathrm{P})$, rough-hydrophobic sand blasted acid etched (SLA) and rough-hydrophilic (modSLA) Ti surfaces. The implant surfaces were manufactured discs of $1.8 \mathrm{~cm}^{2}$ surface area (diameter $=15$ $\mathrm{mm}$ ) designed for use in a $\sim 1.96 \mathrm{~cm}^{2}$ well of a 24 -well tissue culture plate. A detailed overview of the methods of processing these surface modifications along with their physical and chemical characterization is outlined by Rupp et al. [6]. In brief, the Ti discs were punched out from sheets of commercially pure $\mathrm{Ti}$ (of grade III). The crude discs were polished to a mirror on one side with $\mathrm{SiO}_{2}$ grinding paper with a grit diameter of $15-600 \mu \mathrm{m}$. These discs were further treated with diamond paste in oil and finally with a $\mathrm{SiO}_{2}$ suspension to obtain a fine mirrorlike surface. The polished Ti surface has been analyzed by scanning electron microscopy to have a Ra value, representing the average vertical distance between the lowest and highest points within topography, of $0.6 \mu \mathrm{m}$. The SLA discs were prepared by blasting a polished surfaces with large alumina particles, average in a diameter by $250 \mu \mathrm{m}$, and then acid-etching in a hot solution of hydrochloric $(\mathrm{HCl})$ and sulphuric $\left(\mathrm{H}_{2} \mathrm{SO}_{4}\right)$ acids. Following acid etching, the discs would be washed several times in de-ionised water and air dried. The modSLA surface was produced on polished discs with a method similar to that used for the SLA surface, with the exception of the final rinse being conducted under nitrogen protection. By minimizing chances of contamination by atmospheric oxygen and organic chemical moieties, the modSLA has a higher surface energy. The modified discs were supplied sealed in glass tubes, immersed in isotonic $\mathrm{NaCl}$ at $\mathrm{pH}$ 4-6. The arithmetic mean $\mathrm{R}_{\mathrm{a}}$ value of the SLA and modSLA titanium surfaces is reported to be similar at $3.22+0.88 \mu \mathrm{m}$ [6]. The hydrophilicity due to high surface energy of the modSLA surface has been evaluated with advancing contact angle measurements to be $91.31,139.88$ and 0 degrees for the polished, SLA and modSLA surfaces, respectively [6]. The P and
SLA discs required passivation prior to use by immersing discs in $10 \%$ $(\mathrm{v} / \mathrm{v})$ nitric acid in de-ionised water, followed by air-drying and then sterilisation with UV radiation. The modSLA discs were supplied in sealed vacuum glass vials containing sterile saline and were handled submerged in liquid until the point of cell seeding.

\section{Cell culture}

The human bone marrow derived mesenchymal stromal cells (hMSCs) were from three healthy unrelated donors (Caucasian; Male; 20-30 years old) and were obtained from the Institute for Regenerative Medicine, Texas A\&M Health Science Centre, College of Medicine (USA). The cells were isolated from bone marrow aspirates by density centrifugation and tissue culture plastic adherence. The hMSCs had been pre-characterised for colony forming units, osteogenic, chondrogenic and adipogenic differentiation, and expression of a repertoire of stromal cell surface markers. The cells were cultured as described in previously $[28,29]$. In brief, cells were expanded at a low density $(100$ cells per $\mathrm{cm}^{2}$ ) in growth medium (GM) consisting of Minimal Essential Medium alpha (Gibco, UK) supplemented with 10\% (v/v) lot-selected fetal calf serum (Gibco), 1\% (v/v) antibiotics (Penicillin/Streptomycin; PAA Laboratories) and $0.1 \%(\mathrm{v} / \mathrm{v})$ fungicide (Amphotericin B; Gibco). Cell expansion was carried out in $150 \mathrm{~cm}^{2}$ tissue culture (TC) treated flasks (Nunc) at $37^{\circ} \mathrm{C}$ and $5 \% \mathrm{CO}_{2}$ with twice weekly medium changes. Cultures attaining $80 \%$ confluence were detached with a solution of $0.05 \% / 0.002 \%$ Trypsin/EDTA in $\mathrm{Ca}^{+2} / \mathrm{Mg}^{+2}$-free PBS (PAA Laboratories). Experiments were performed using cells that had undergone a maximum of three passages. Osteogenic differentiation was induced by culturing cells in osteogenic medium (OM) comprising Dulbecco's Modified Eagle's Medium low glucose supplemented with $10 \%(\mathrm{v} / \mathrm{v})$ lot-selected fetal calf serum (Gibco), $1 \%(\mathrm{v} / \mathrm{v})$ antibiotics and $0.1 \%(\mathrm{v} / \mathrm{v})$ fungicide (Gibco), $10 \mathrm{nM}$ dexamethasone (water soluble; Sigma-Aldrich), $10 \mathrm{mM} \quad \beta$-glycerolphosphate (Fischer Scientific) and $50 \mu \mathrm{M}$ ascrobate-2-phosphate (Fluka). Recombinant proteins were applied to deregulate AXL receptor signalling as previously described [23]. The agonist was recombinant human Gas6 (885-GS; $\mathrm{R} \& \mathrm{D}$ Systems) that was supplemented in $\mathrm{OM}$ at a final concentration of $0.25 \mu \mathrm{g} / \mathrm{ml}$. The antagonist (MAb) consisted of three molecules; recombinant human AXL extracellular domain (AXL-ECD) (154-AL$\mathrm{x} ; \mathrm{R} \& \mathrm{D}$ Systems), and blockade monoclonal antibodies against receptor (AF154; R\&D Systems) and ligand (AB885; R\&D Systems). The final concentrations of these components was as follows; AXL-ECD $4 \mu \mathrm{g} /$ $\mathrm{ml}$; anti-AXL blockade monoclonal antibodies $2.5 \mu \mathrm{g} / \mathrm{ml}$; and antiGAS6 monoclonal antibodies $10 \mu \mathrm{g} / \mathrm{ml}$. Cell proliferation was assessed with the AlamarBlue (Abdserotec) assay as described in [17]. Briefly, viable cells were incubated with $10 \%(\mathrm{v} / \mathrm{v})$ AlamarBlue dye in medium for $4 \mathrm{~h}$. A $100 \mu \mathrm{l}$ aliquot of conditioned medium was transferred to an opaque 96-well microtitre plate and fluorescence intensity determined at excitation $530 \mathrm{~nm}$ and emission $590 \mathrm{~nm}$.

\section{Gene expression analysis of AXL and GAS6}

Transcriptional changes in AXL, GAS6 and their relevant downstream effector TWIST1 were examined at 1, 3 and 7 days post seeding by real time polymerase chain reaction (RTPCR) using the delta $\mathrm{Ct}$ method. For this analysis, hMSCs $(\mathrm{N}=3)$ were seeded at a density of $2.5 \times 10^{4}$ cells per surface in $1 \mathrm{ml}$ medium in triplicate in 24 well plates (Nunc). The surfaces tested were tissue culture plastic, P, SLA and modSLA Ti discs. The analysis was conducted with GM and OM as these media may variably affect the signalling pathway. Total RNA was extracted with the Qiagen RNeasy Mini kit (Qiagen) according to the manufacturer's instructions. The integrity and quantity of extracted RNA was evaluated by spectrophotometery $(\lambda 260: \lambda 280 \mathrm{~nm} ; \mathrm{M} 200$, 
Tecan). A total of $400 \mathrm{ng}$ of RNA per sample was converted to 100 $\mu \mathrm{l}$ cDNA by first strand synthesis reactions using the High Capacity Reverse Transcription Kit (Applied Biosystems) according to the manufacturer's instructions. RTPCR reactions were performed in a 7300 Real Time PCR System (Applied Biosystems) in $25 \mu$ l reactions with $2.5 \mu \mathrm{l}$ of cDNA per reaction (10 ng of RNA equivalent). Human specific Taqman probes for the three genes were used at $1.25 \mu \mathrm{l}$ per reaction. The Taqman probes used were AXL (Hs01064444_m1), GAS6 (Hs01090305_m1) and TWIST1 (Hs00361186_m1) (all from AppliedBiosystems). The Ct values of markers were normalised to the GAPDH house keeping gene and calibrated to $\Delta \mathrm{Ct}$ values of cells in suspension (at time zero) to obtain relative fold values of expression.

\section{Protein examination of AXL and GAS6}

ELISA was used to quantify AXL and GAS6 proteins at 1, 3 and $7 \mathrm{~d}$ post seeding as it allowed a quantitative estimate as opposed to a semiquantitative output of a western blot. Three donors were examined separately in two different media conditions (GM and OM). Samples were formed in 24 well plates by seeding hMSCs at a density of $2.5 \times 10^{4}$ cells per surface in $1 \mathrm{ml}$ of medium on TCP, P, SLA and modSLA; in 6 replicates $(n=6)$ per time point per condition per donor, for later pooling as the pooling of multiple replicates was required to yield minimally detectable levels of protein for the sensitivity of the ELISA kits.

Total and tyrosine phosphorylated AXL were quantified in pooled cellular homogenates using two kits (R\&D Systems; DYC1643-2; DYC2228-2, respectively). For this cell monolayers were washed twice with PBS and lysed in situ by adding $100 \mu \mathrm{l}$ of lysis buffer per sample well for 15 minutes on ice. The lysis buffer comprised $20 \mathrm{mM}$ Tris (pH 8.0), $137 \mathrm{mM} \mathrm{NaCl}, 10 \%$ glycerol, $2 \mathrm{mM}$ EDTA, $1 \mathrm{mM}$ activated sodium orthovanadate, $10 \mu \mathrm{g} / \mathrm{ml}$ Aprotinin, and $10 \mu \mathrm{g} / \mathrm{ml}$ Leupeptin (all Sigma). The homogenates of sample replicates were then pooled and stored at $-80^{\circ} \mathrm{C}$. Samples were assayed by centrifuging at $2000 \mathrm{xg}$ for 5 minutes and testing $100 \mu \mathrm{l}$ supernatant per each ELSIA kit as per manufacturer's instructions.

The soluble GAS6 molecule was quantified with ELISA (R\&D Systems; Dy88g). For this purpose, culture medium was collected and pooled $(n=6)$ following replacement every day for seven days. After each medium collection, cell numbers were estimated with the AlamarBlue assay as described above and medium re-replaced for the following 24 hour period. The pools of medium were frozen at $-80^{\circ} \mathrm{C}$ for later lyophilisation in a freeze dryer. The resulting mass was reconstituted in $0.5 \mathrm{ml}$ deionised water. The total amounts of AXL and GAS6 measured were normalised to estimated cell numbers.

\section{Effects of AXL pathway de-regulation on extracellular matrix calcium mineralisation}

The effect of AXL/GAS6 signalling on osteogenic mineralisation was assessedby two methods; a semi-quantitative assay using Alizarin Red S (Sigma) staining; and a quantitative determination of extra cellular matrix calcium using the QuantiChrom calcium assay kit (DICA 500, Universal Biologicals). For the Alizarin red measurements cells were seeded at a density of $6 \times 10^{5}$ per $9.6 \mathrm{~cm}^{2}$ in a 6-well plate and cultured for 14 days under the following four conditions: growth medium (GM), osteogenic medium (OM), OM with antagonist and $\mathrm{OM}$ with agonist. Staining was conducted by initially fixing monolayer in $4 \%$ paraformaldehyde in PBS for 30 minutes at room temperature followed by two washes in PBS. To each well, $3 \mathrm{ml}$ of $2 \%$ Alizarin stain in deionised water ( $\mathrm{pH} 4.1$ ) were added for $20 \mathrm{~min}$ and then washed with copious amounts of water. Samples were air dried and scanned on a flatbed scanner (Epsom photo, 4200). For the QuantiChrom assays hMSCs were cultured in 24 well plates on TCP, P, SLA and modSLA surfaces in OM only, and OM with agonist or antagonist in triplicate at a density of $2.5 \times 10^{4}$ cells per well. After seven days, AlamarBlue assays were conducted to estimate cell numbers followed by homogenisation of monolayer in $1 \mathrm{M} \mathrm{HCl}$ in deionised water for 10 min at room temperature. A $5 \mu$ l volume of each sample was assayed as manufacturer's instructions. The calcium quantities determined were normalized to total cell numbers estimated by the AlamarBlue assays.

\section{Effects of AXL pathway de-regulation on extracellular matrix collagen deposition}

The formation of ECM collagen was measured after $7 \mathrm{~d}$ in culture with the Sircol Collagen assay kit (Biocolor, UK). The cells were seeded at a density of $2.5 \times 10^{4}$ cells per surface in 24-well plates in triplicate on TCP, P, SLA and modSLA in OM alone, and OM with agonist or antagonist. Samples were homogenised with $400 \mu$ of cold $0.5 \mathrm{M}$ acetic acid (Sigma) supplemented with $100 \mu \mathrm{g} / \mathrm{ml}$ porcine pepsin (Sigma-Aldrich) for 10 minutes at room temperature. Homogenates from three replicate wells were pooled and concentrated overnight with $200 \mu \mathrm{l}$ Isolation and concentration reagent at near $0^{\circ} \mathrm{C}$. The pooling of samples was required due to the small amounts of collagen formed by cells in individual wells. Concentrated pooled replicates of a sample were centrifuged to pellet the collagen and the albumin rich supernatant was discarded. Collagen pellets were stained with Sirius red in picric acid for $30 \mathrm{~min}$ and later washed in acid-salt solution to remove excess unbound dye. Bound stain was eluted with $250 \mu \mathrm{l}$ of an alkali solution. The absorbance of $200 \mu \mathrm{l}$ of each sample was measured at $555 \mathrm{~nm}$ in a clear micro titer plate. Total quantities were determined by interpolating absorbance values from a 6 point standard curve.

\section{Effects of AXL pathway de-regulation on osteoblastic soluble marker levels}

ELISA assays were used to quantify the levels of soluble osteoblastic markers osteoprotegrin (OPG) and growth differentiation factor 15 (GDF-15) in culture supernatant. The cells were seeded at $2.5 \times 10^{4}$ cells per surface on TCP, P, SLA and modSLA in OM, OM with agonist or $\mathrm{OM}$ with antagonist. Culture supernatant was collected and replaced every 24 hours for $7 \mathrm{~d}$. Samples were diluted 1:10 in deionised water to assay for OPG (R\&D Systems; DY805) and GDF-15 (R\&D Systems; DY957), according to the manufacturer's instructions. Quantities were normalised to total cell numbers estimated with the AlamarBlue assay.

\section{Statistical analysis}

Statistical analysis of data was undertaken with the Graphpad Prism v5.02 software. Experiments were conducted with three donors $(\mathrm{N}=3)$ with number of replicates indicated by $(\mathrm{n})$. Data was analysed with a 2-way ANOVA followed by Bonferroni post-test.

\section{Results}

\section{Gene expression of AXL, GAS6 and TWIST1 on different surfaces}

All genes displayed very low fold expression in hMSCs (Figure 1). AXL was expressed at similar levels in all conditions at $1 \mathrm{~d}$ and displayed a small increase in transcription at $3 \mathrm{~d}$ post seeding, returning to base line levels by $7 \mathrm{~d}$. GAS6 did not display noticeable transcriptional changes though it was expressed relatively higher in OM than GM. TWIST1 displayed varied results with its expression higher in GM 
a. AXL expression GM

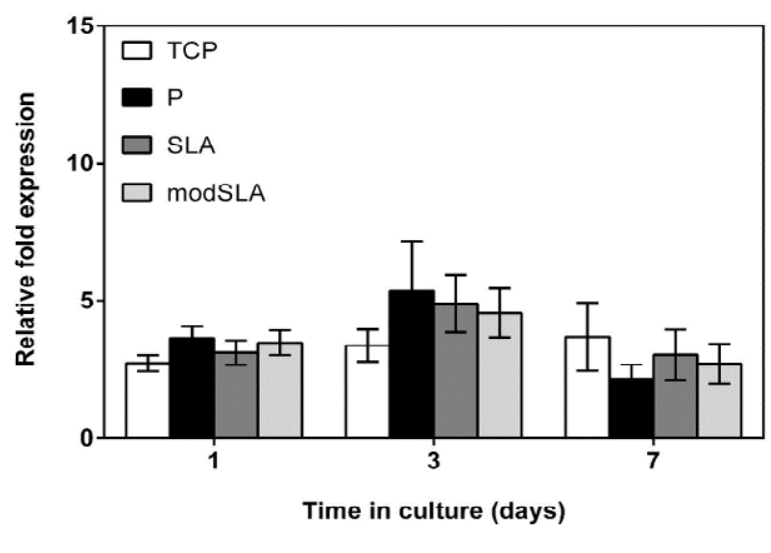

c. GAS6 expression GM

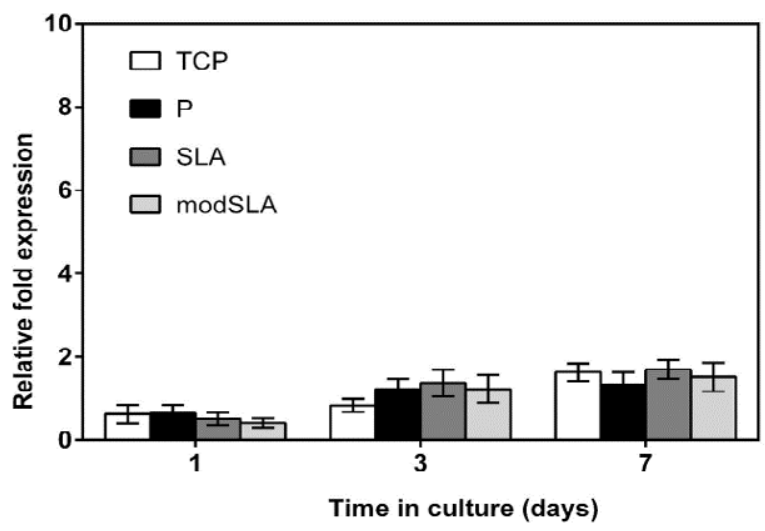

e. TWIST1 expression GM

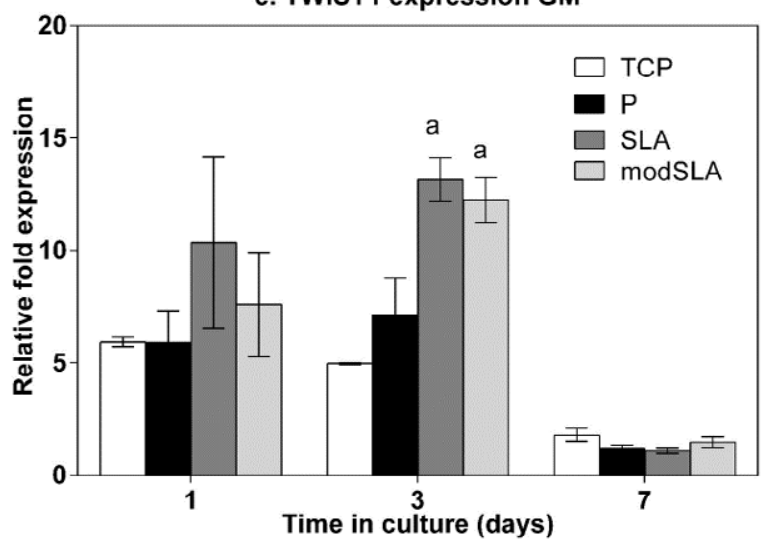

b. AXL expression OM

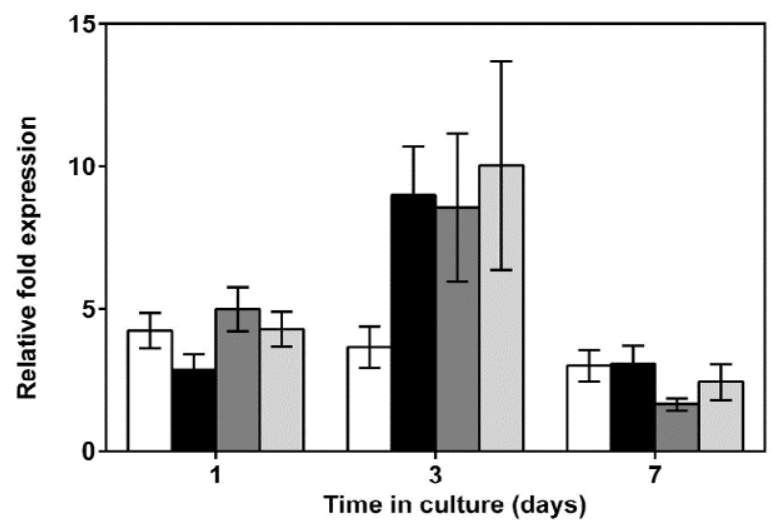

d. GAS6 expression OM

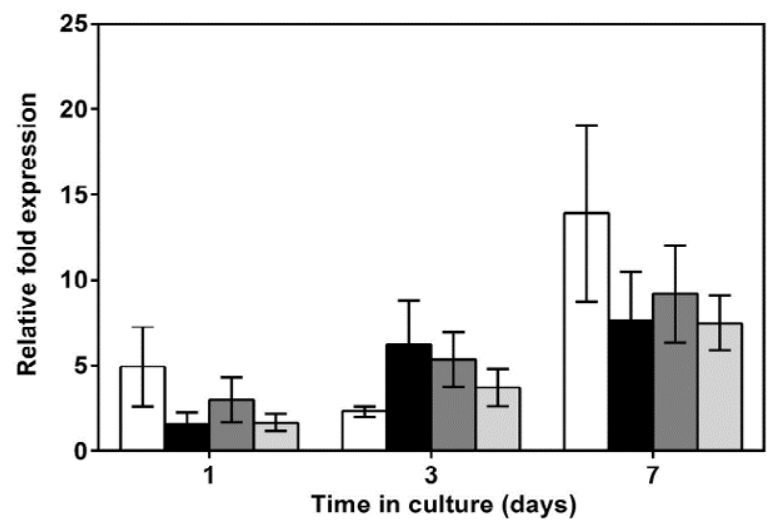

d. TWIST1 expression OM

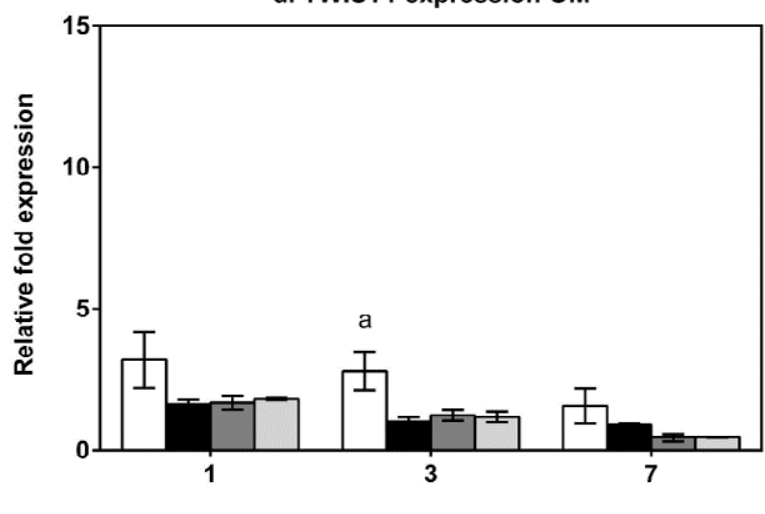

Time in culture (days)

Figure 1: Gene expression assayed in hMSCs were cultured in growth (GM) or osteogenic (OM) media on TCP, P, SLA and modSLA Ti surfaces at 1,3 and 7 days post seeding showed small fold expression of all genes. AXL $(a, b)$ and GAS6 (c,d) did not display any surface specific changes in expression, although the ligand was transcribed relatively higher in OM than GM. TWIST1 $(e, f)$ displayed surface specific differences in expression, being significantly up-regulated by rough compared to smooth at $3 \mathrm{~d}(p<0.05)$ in GM. The gene was expressed at relatively higher levels on TCP than $\mathrm{Ti}$ at $3 \mathrm{~d}$ in $\mathrm{OM}$. Bars represent mean $\pm \mathrm{SEM}$; $\mathrm{N}=\mathrm{donors}=3$, $\mathrm{n}=$ replicates $=3 .{ }^{\mathrm{a}}=p<0.05$, TCP vs. Ti surface.

than OM. However at $3 \mathrm{~d}$ its expression had significantly increased on the rough surfaces compared to smooth. Furthermore, OM caused a decline in its transcription on all surfaces.

\section{Protein changes in AXL and GAS6 on different surfaces}

The quantities of total and tyrosine phosphorylated AXL, and soluble ligand GAS6 were quantified in pools of six replicates of human
MSCs cultured on TCP, P, SLA and modSLA in osteogenic medium (Figure 2). Cellular AXL was initially detected at near similar levels on all surfaces. TCP cultured cells displayed a highly significant $(p<0.001)$ increase in AXL total protein and tyrosine phosphorylation compared to $\mathrm{Ti}$. Comparisons between the $\mathrm{Ti}$ surfaces showed the rough significantly decreased receptor quantities compared to $\mathrm{P}$ at $3 \mathrm{~d}$ and $7 \mathrm{~d}$, which was corroborated by the relatively lower levels of receptor 
a. Total AXL protein per cell
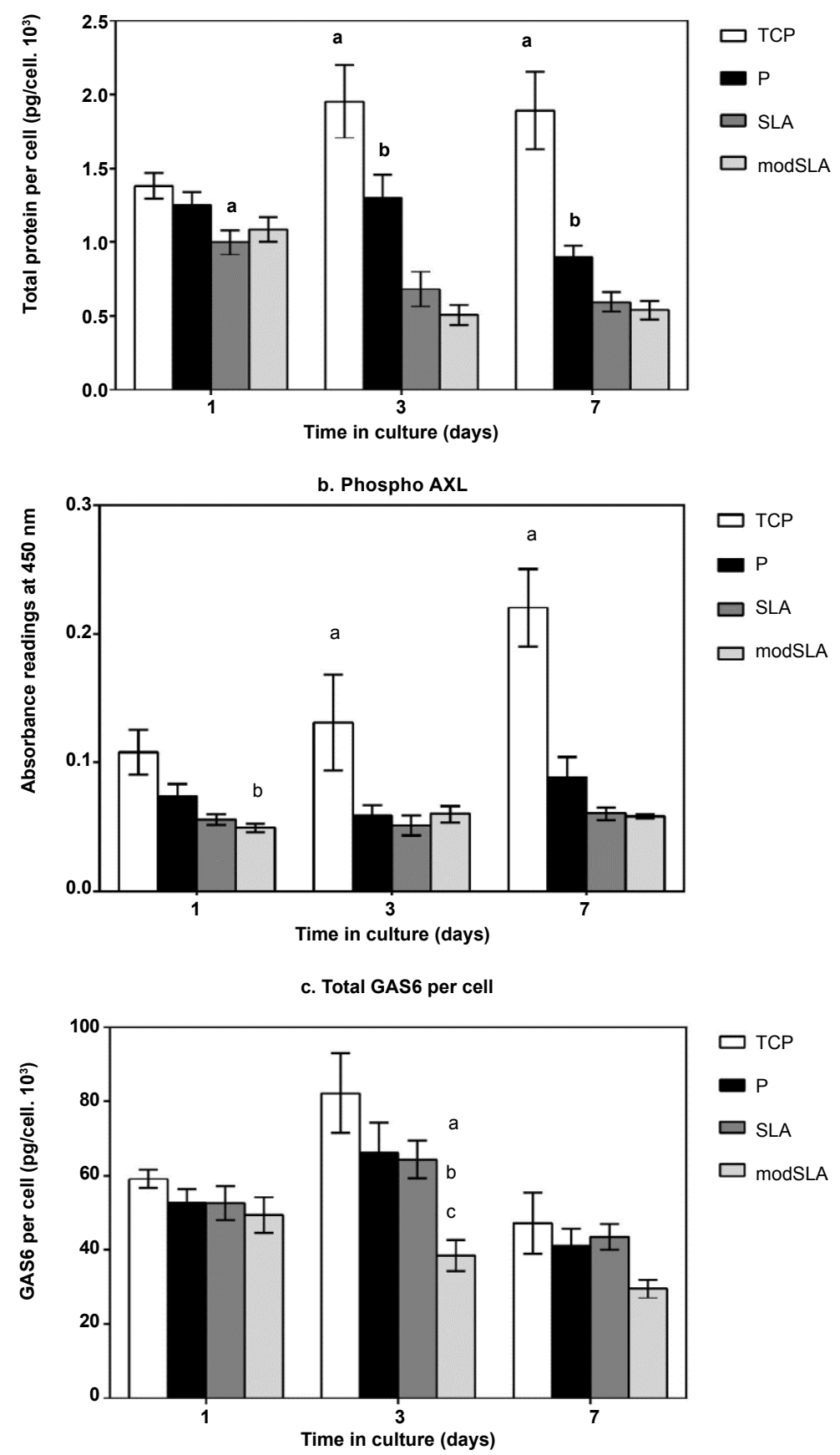

Figure 2: Protein expression analysis of AXL, GAS6 in hMSCs cultured on all surfaces for 7 days. (a) Axl protein was detected at similar levels on all surfaces at 1 d. Total receptor protein significantly decreased on the rough by 3 and 7 days compared to smooth. This down-regulation occurred later on $P$ surface compared to rough. (b) AXL tyrosine phosphorylation was significantly lower on Ti than TCP. (c) GAS6 was similar in all samples at $1 \mathrm{~d}$ and its levels increased on all surfaces except modSLA by $3 \mathrm{~d}$. At $7 \mathrm{~d}$ GAS6 levels had reduced to below initial readings on all surfaces. Bars shows mean $+1 \mathrm{SD} ; \mathrm{N}=3, \mathrm{n}=1 .{ }^{\mathrm{a}}=p<0.05, \mathrm{TCP}$ vs. Ti surface. $\mathrm{b}=p<0.05$, polished P Ti vs. Rough Ti surface. ${ }^{c}=p<0.05$, SLA vs. modSLA.

phosphotyrosine estimates at $1 \mathrm{~d}$ and $7 \mathrm{~d}$ on the rough vs. smooth $(p<0.05)$. The secreted cytokine Gas6 was present at similar levels on all surfaces at $1 \mathrm{~d}$. Its levels increased on TCP, P and SLA surfaces at $3 \mathrm{~d}$, while decreasing significantly on the modSLA. Quantities of the cytokine decreased on all surfaces by $7 \mathrm{~d}$, but were observably lower on the modSLA compared to all other surfaces.

\section{Effects of AXL pathway deregulation on extracellular calcium mineralisation}

An Alizarin Red S stained digital scan of hMSCs cultured in 6 well plates in either growth medium (GM), osteogenic medium (OM), OM with antagonist, $\mathrm{OM}$ with agonist or with both is presented in Figure 3a. The GM and OM cultured control samples displayed negative and 

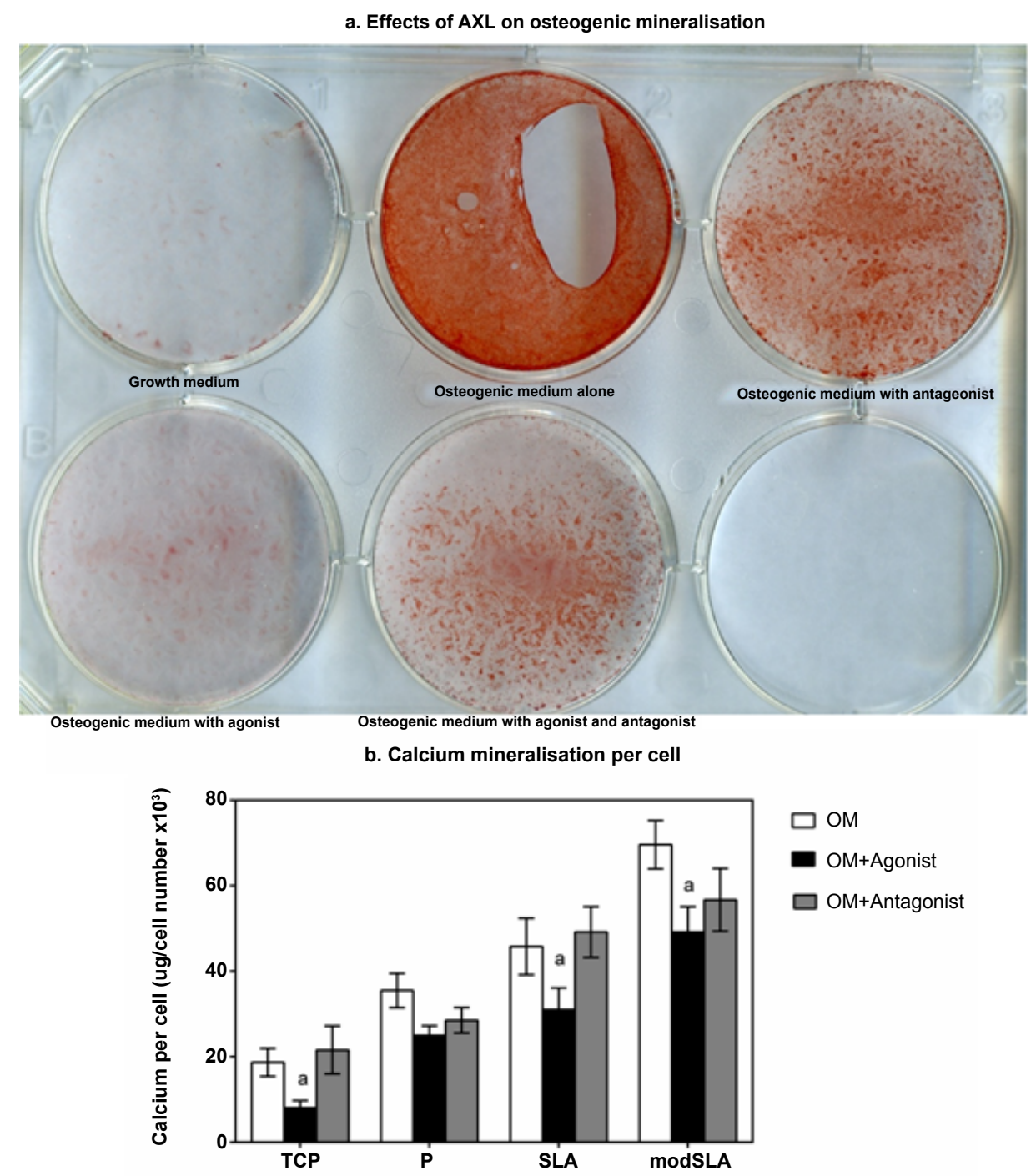

Surface (duration in culture of 7 davs)

Figure 3: Effects of AXL signaling disruption on extracellular matrix calcium mineralisation were assayed. (a) hMSC cultured in different conditions for 14 days and stained with a $2 \%$ Alizarin Red S were imaged on a flatbed scanner. GM showed no stain. OM stained intensely. Antagonist stained positive though intensity was lesser than OM alone. The agonist had caused a strong decline in staining intensity compared to control and OM with antagonist. The combination of both media supplements led to an intermediate stain. (b) Cells were cultured on all surfaces with OM, OM with agonist or OM with antagonist for $7 \mathrm{~d}$; calcium quantities and cell numbers assayed. Control OM induced mineralisation in an order of modSLA > SLA > P > TCP. The additions of agonist significantly decreased mineralisation on each surface respective to controls; but did not inhibit the process. This effect was most prominent on the TCP. The addition of antagonist did not increase calcium mineralisation on all surfaces; $\mathrm{P}$ and modSLA cultured cells displayed a small decrease in presence of antagonist. Error bars show mean \pm 1 SD; $\mathrm{N}=3, \mathrm{n}=3 .{ }^{a}=p<0.05$, control vs. condition for any surface.

positive stained monolayers, respectively. The OM with antagonist stained positive for Alizarin but stain intensity was visibly lower than the control OM. The OM with agonist cultured cells displayed a stark decline in stain compared to control and $\mathrm{OM}$ with antagonist while their combination yielded an intermediate stain. In the second analysis, the amount of calcium per cell was determined with a colorimetric assay. The result of this experiment is shown in Figure 3b. It demonstrates that human MSCs mineralise along the previously reported trend for the control condition, OM only, by depositing higher mineral on modSLA than SLA than P than TCP. The addition of receptor agonist decreased the quantity of calcium per sample relative to its control though the trend of higher mineralisation on modSLA $>$ SLA $>$ P $>$ TCP was still preserved. This down-regulation in mineralisation was strongly evident in the TCP sample as that substrate fails to induce osteogenic mineralisation at a level comparable with the Ti surfaces.

\section{Effects of AXL pathway deregulation on matrix collagen formation}

The ECM collagen formed by samples was estimated at 7 days post seeding. The results of this analysis are illustrated in Figure 4a. It indicates collagen synthesis was similar between all surfaces and not affected by AXL deregulation. Previously reported ratios of calcium to collagen for control medium [17] were observed again. The antagonist was found to have a small yet significant increase in calcium per collagen on the modSLA surface only. The decline in mineral content upon TCP in the presence of agonist was evident by the observation of the lower calcium per collagen ratio (Figure $4 b$ ). 


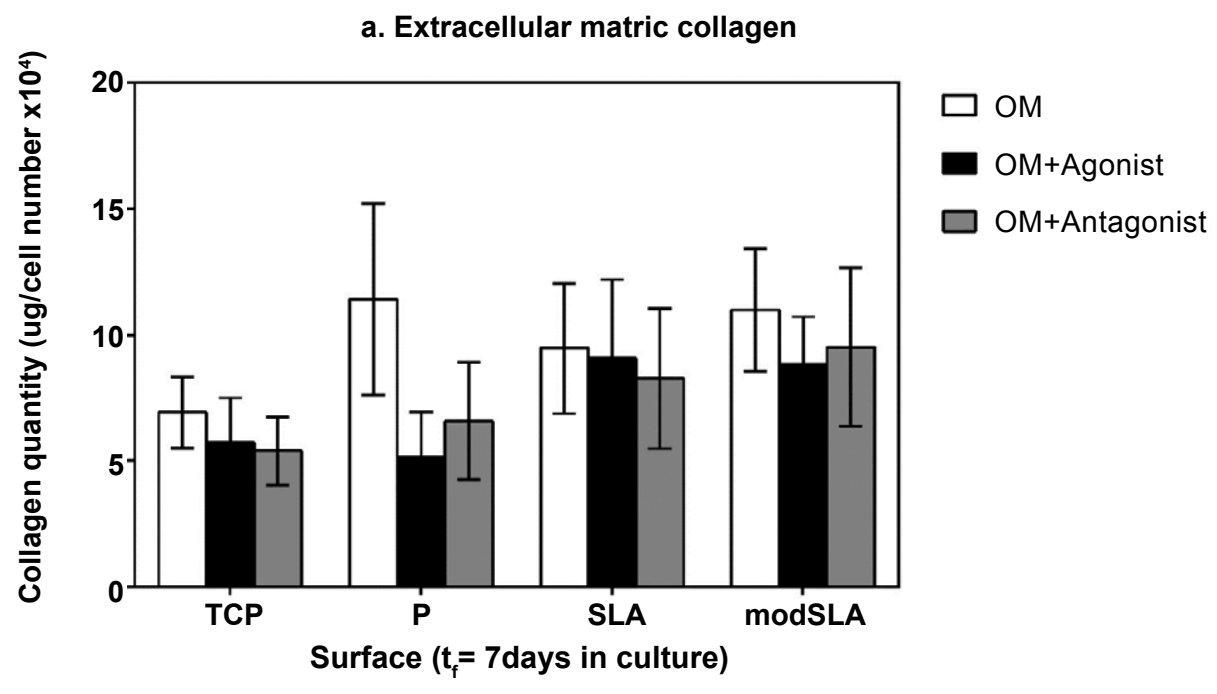

b. Calium per Collagen

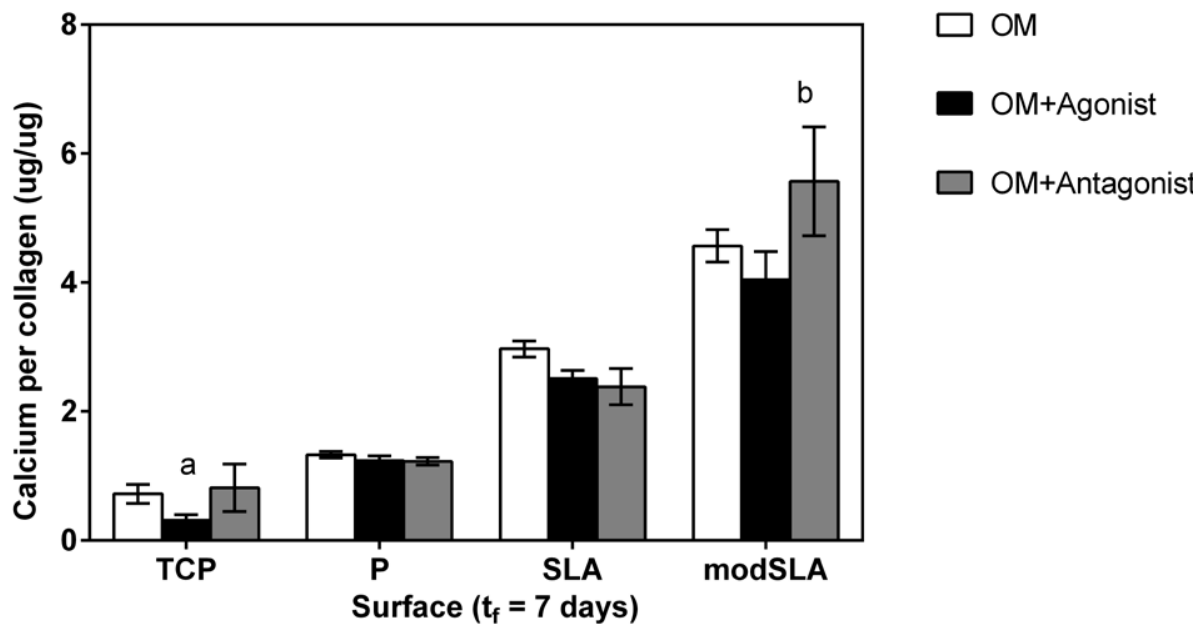

Figure 4: Effects of AXL deregulation on cellular collagen synthesis showed that (a) total collagen is not affected by receptor deregulation does not affect collagen synthesis. (b) The ratio of total ECM calcium to collagen indicated receptor agonist decreased ECM calcium content on TCP. This was not detected for P. The ECM calcium content on rough was relatively decreased by receptor agonist. The modSLA seeded cells deposited a relatively higher calcified ECM with receptor antagonist. Error bars show mean $\pm 1 \mathrm{SD} ; \mathrm{N}=3, \mathrm{n}=1 .{ }^{\mathrm{a}}=p<0.05$, control vs. Condition. ${ }^{\mathrm{b}}=p<0.05$, agonist vs. antagonist.

\section{Effects of AXL pathway deregulation on soluble osteoblastic marker levels}

The osteoblast associated cytokines OPG and GDF-15 were quantified in culture supernatants of hMSCs on the different surfaces in control, agonist or antagonist supplemented media (Figure 5). The OPG was expressed at a similar level by all samples at this time in control medium $\mathrm{OM}$ only. Both conditions inducing receptor deregulation had modulated an increase in OPG soluble levels. This increase was statistically significant for antagonist compared to osteogenic medium only control cultured cells of every surface. Statistically highest level of soluble OPG was detected in cells cultured on the rough surfaces than all samples. A similar trend was observed for GDF-15. Its secretion was relatively higher on the rough compared to smooth control in medium. Receptor agonist did not affect GDF-15 soluble levels compared to controls. However, the antagonist relatively increased its levels compared to control medium. This increase was relatively pronounced in cells on the rough surfaces compared to smooth.

\section{Discussion}

Previous studies have examined the cellular responses to the SLA and modSLA Ti implant surfaces in an attempt to understand the cellular and molecular events that underlie their different performance in vivo, however, more recently studies have assessed the possibilities offered for bone related tissue engineering. These studies have examined whether the modified Ti substrates influence sub-cellular processes that manifest in an enhancement of osteogenic differentiation and function. The present study evaluated if the tyrosine kinase receptor AXL and its ligand GAS6 were differentially modulated during osteogenesis in human MSCs cultured on the SLA and modSLA Ti surfaces. AXL has been previously shown to have osteo-inhibitory effects on the in vitro mineralisation of uncommitted pericytic cells [23] and the reduction in endothelial ectopic calcification in vivo from the re-constitution of signalling by statins [26]. It is suggested that AXL has an important role preceding osteogenenic induction, being down regulated with the initiation and progression of calcium mineralisation [24]. In this study, genetic and protein changes to AXL and GAS6 were examined in cells 
a. Effects of AXL on soluble OPG levels
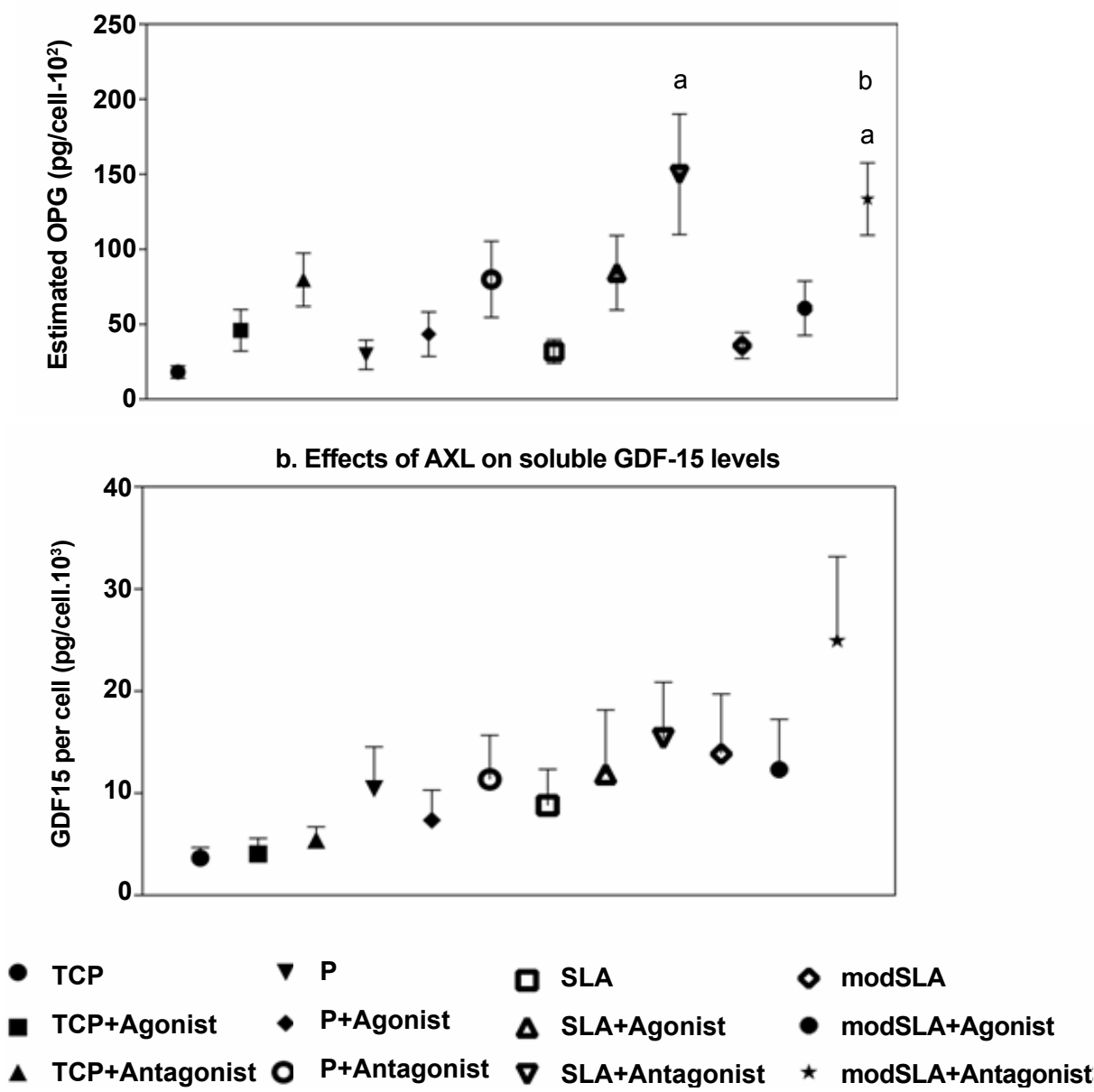

Figure 5: Effects of AXL receptor deregulation on OPG synthesis showed that (a) receptor antagonist increased OPG levels by $7 \mathrm{~d}$ on all surfaces compared to control osteogenic medium alone. The levels were statistically highest on antagonist-rough cultured cells. (b) Receptor antagonist similarly affects levels of soluble GDF-15 compared to osteogenic medium only control. However, changes were not statistically significant. Bars show mean $\pm \mathrm{SEM} ; \mathrm{N}=3, \mathrm{n}=3$. ${ }^{a}=p<0.05$, control vs. any of the two conditions. ${ }^{\mathrm{b}}=p<0.05$, agonist vs. antagonist.

cultured on four experimental surfaces, with a further evaluation of the effects of this pathway's deregulation on osteogenic differentiation with receptor agonist or antagonist molecules that could increase or decrease signalling, respectively.

It was shown that AXL and GAS6 were differentially expressed by cells in response to the different surfaces they were cultured on. This difference was far less obvious at the transcript level but stark at the protein level, with significant reductions in both total AXL and tyrosine phosphorylated AXL proteins on the rough surfaces compared to smooth in culture. Changes in transcription of the GAS6 gene were nominal over the time course; however, the soluble protein was detected at higher levels in osteogenic differentiation than control medium and, similar to the AXL protein, showed a comparative reduction on the modSLA and SLA rough surfaces compared to smooth over time in culture. These observations suggests that cells on the rough surfaces were undergoing an enhancement in osteogenic differentiation and therefore down-regulated the osteo-inhibitory activity of AXL in order to initiate the earlier deposition of extracellular matrix. Clinical in vivo studies utilising gene expression arrays have shown an earlier upregulation of key osteogenic markers in response to modified implant surfaces, adding weight to the hypothesis that modified surfaces may induce a de novo enhancement in osteogenic differentiation and activity [12-14]. This hypothesis is corroborated by the observation of the down-regulation of TWIST1 gene expression in osteogenic medium relative to control medium and was later found to be inversely proportional to the extent of cellular mineralisation achieved after seven days.

The effects of deregulating AXL signaling in hMSCs demonstrated the importance of the pathway in osteogenic differentiation, as well as the significance of its differential modulation in cells on the different surfaces. The agonist induced a decrease in calcium mineralisation on all surfaces that was significant only in the case of TCP cultured cells, possibly due to the reduced level of differentiation and matrix mineralisation seen on this surface compared to rough. The significant increase in the levels of soluble osteogenic markers on the rough surfaces caused by down-regulating AXL signaling by the receptor antagonist suggests these osteoclastogenic inhibitors may partly underpin the significant rise in peri-implant bone accrual seen for modSLA and SLA implants in vivo $[7,8]$. Furthermore, the expression and reduction in activity in hMSCs with the progression of osteogenic differentiation, implicates AXL with the maintenance of hMSC stemness.

Osteogenic differentiation is not a simple one-step process with a single path of initiation; rather it appears to be the net effect 
of several separate cellular processes, each possibly being induced by a single event of commitment. The findings here and in previous studies show the importance of both the substrate and its topography on the osteogenic differentiation of uncommitted cells in vitro [15$17,19]$. Though the extent to which these observations truly replicate osteogenesis in vivo remains debatable, the fact that they are taking place on a material whose very basis of in vivo application is its ability to accrue bone matrix compared to the synthetic non-biological tissue culture plastic widely used in vitro cell biology, gives weight to the theory of de novo 'accelerated osteogenesis' proposed previously [15]. The important underlying molecular mechanisms governing the differential modulation of AXL are of high importance. Though the receptor is ubiquitously expressed in several uncommitted cell types, the dynamics of ligand GAS6 expression, promoter control and post translational activation, particularly in osteogenesis, are still poorly understood [22]. In addition, the present data set is insufficient to draw a discrete association between the pathway and a specific cellular response that may result in osteo-inhibition. Never the less, the correlation of its differential modulation with the onset and degree of mineralization strongly suggests a close association between the pathway and MSC commitment to an osteogenic lineage.

One might also infer from the findings in this study that the use of titanium substrates will provide a better in vitro model for bone related drug discovery, since their behaviour in vivo is well studied, making correlation between in vivo an in vitro effects more relevant than that on TCP. Furthermore, as a putative marker for assessing bone implant surface design, understanding the dynamics of AXL signaling and its regulation may shed light on the mechanisms governing the different osteogenic responses observed on the Ti substrates and therefore aid in developing strategies to enhance titanium's applications in bone tissue engineering.

\section{Conclusion}

The receptor AXL and its ligand GAS6 are expressed at genetic and protein levels in human MSCs prior to differentiation. With the induction and progression of osteogenic differentiation, these signaling components are down-regulated in vitro with a clear correlation to the clinical efficacy of the Ti implant surfaces in vivo, suggesting AXL might be a surrogate marker for material/surface efficacy for the assessment of future implant surface design and development.

\section{Acknowledgements}

The authors acknowledge the following: Ann Canfield, School of Medicine, University of Manchester, for her technical advice; Mohamed Hussein Parkar from UCL EDI for his technical assistance. This work was funded by ITI Foundation grant \# 491/2006.

\section{References}

1. Liu X, Chu P, Ding C (2004) Surface modification of titanium, titanium alloys, and related materials for biomedical applications. Mat Sci Eng 47: 91-121.

2. Wennerberg A, Albrektsson T (2009) Effects of titanium surface topography on bone integration: a systematic review. Clin Oral Impl Res 20: 172-182. [PubMed]

3. Zhao G, Raines A, Wieland M, Schwartz Z, Boyan B (2007) Requirement for both micron and sub-micron scale structure for synergistic responses of osteoblasts to substrate energy and topography. Biomat 31: 2728-2735. [PubMed]

4. Rausch-Fan X, Qu Z, Wieland M, Matejka M, Schedle A (2007) Differentiation and cytokine synthesis of human alveolar osteoblasts compared to osteoblast like cells in response to titanium surfaces. Dent Mater 24: 102-110. [PubMed]

5. Brett P, Harle J, Salih V, Mihoc R, Olsen I, et al. (2004) Roughness response genes in osteoblasts. Bone 35: 124-133. [PubMed]
6. Rupp F, Schneider C, Olshanska N, de Wild M, Wieland M, et al. (2006) Enhancing surface free energy and hydrophilicity through chemical modification of microstructured titanium implant surfaces. J Biomed Mater Res 76: 323-334 [PubMed]

7. Schwartz F, Wieland M, Schwartz Z, Zhao G, Rupp F, et al. (2009) Potential of chemically modified hydrophilic surface characteristics to support tissue integration of titanium dental implants. J Biomedi Mat Res 88: 544-557. [PubMed]

8. Bornstein M, Wittneben J, Bragger U, Buser D (2010) Early loding at 21 days of non-submerged titanium implamts with a chemically modified sandblasted and acid-etched surface: 3 -year results of a prospective study in the posterior mandible. J Periodontal 81: 809-818. [PubMed]

9. Schwartz F, Sager M, Kadeka I, Ferrari D, Becker J (2010) Influence of titanium implant surface characteristics on bone regeneration in dehiscence type defects: an experimental study in dogs. J Clin Periodontol 37: 466-473. [PubMed]

10. Lang N, Salvi G, Huynh-Ba G, Ivanovski S, Donos N, et al. (2011) Early osseointegration to hydrophilic and hydrophobic implant surfaces in humans. Clin Oral Impl Res 22: 349-356. [PubMed]

11. Bosshardt D, Salvi G, Huynh-Ba G, Ivanovski S, Donos N, et al. (2011) The role of bone debris in early healing adjacent to hydrophilic and hydrophobic implant surfaces in man. Clin Oral Impl Res 22: 357-364. [PubMed]

12. Donos N, Hamlet S, Lang N, Salvi G, Huynh-Ba G, et al. (2011) Gene expression profile of Gene expression profile of compared with a hydrophobic microrough implant surface. Clin Oral Impl Red 22: 365-372. [PubMed]

13. Ivanovski S, Hamlet S, Salvi G, Huynh-Ba G, Bosshardt D, et al. (2011) Transcriptional profiling of osseointegration in humans. Clin Oral Impl Res 22 378-381. [PubMed]

14. Ivanovski S, Hamlet S, Retzepi M, Wall I, Donos N (2011) Transcriptional profiling of "guided bone regeneration" in a critical-size calvarial defect. Clin Oral Impl Res 22: 382-389. [PubMed]

15. Wall I, Donos N, Calqvist K, Jones F, Brett P (2009) Modified titanium surfaces promote accelerated osteogenic differentiation of mesenchymal stromal cells in vitro. Bone 45: 17-26. [PubMed]

16. Mendonça G, Mendonça D, Aragão F, Cooper L (2008) Advancing dental implant surface technology--from micron- to nanotopography. Biomaterials 29: 3822-3835. [PubMed]

17. Khan M, Donos N, Salih V, Brett $P$ (2012) The enhanced modulation of key bone matrix components by modified Titanium implant surfaces. Bone 50: 1-8. [PubMed]

18. Caplan A (2009) Why are MSCs therapeutic? New data: new insights. J Path 217: 318-324. [PubMed]

19. Olivares-Navarrete R, Hyzy S, Hutton D, Erdman C, Wieland M, et al. (2010) Direct and indirect effects of microstructured titanium substrates on the induction of mesenchymal stem cell differentiation towards the osteoblast lineage. Biomaterials 31: 2728-2735. [PubMed]

20. Olivares-Navarrete R, Hyzy S, Park J, Dunn G, Haithcock D, et al. (2011) Mediation of osteogenic differentiation of human mesenchymal stem cells on titanium surfaces by a Wnt-integrin feedback loop. Biomaterials 32: 6399-6411. [PubMed]

21. Satomura K, Derubeis A, Fedarko N, Ibaraki-O'Connor K, Kuznetsov S, et al. (1998) Receptor tyrosine kinase expression in human bone marrow stromal cells. J Cell Physiol 177: 426-438. [PubMed]

22. Linger R, Keating A, Earp H, Graham D (2008) TAM receptor tyrosine kinases: biologic functions, signaling, and potential therapeutic targeting in human cancer. Adv Can Res 100: 35-83. [PubMed]

23. Collet G, Wood A, Alexander M, Varnum B, Boot-Handford R, et al. (2003) Receptor Tyrosine Kinase Axl Modulates the Osteogenic Differentiation of Pericytes. Circ Res 92: 1123-1129. [PubMed]

24. Collet G, Sage A, Kirton J, Alexander M, Gilmore A, et al. (2007) Axl/ phosphotidylinositol 3-kinase signalling inhibits mineral deposition by vascular smooth muscle cells. Circ Res 100: 502-509. [PubMed]

25. Yoo H, Yoon S, Park S, Lee E, Lee E, et al. (2011) Gene expression profile during chondrogenesis in human bone marrow derived mesenchymal stem cells using a cDNA microarray. J Korean Med Sci 26: 851-858. [PubMed] 
Citation: Khan MR, Donos N, Salih V, Brett PM (2014) Receptor Kinase AXL is Modulated in the Osteogenic Differentiation of Human Mesenchymal Stromal Cells on Modified Titanium Implant Surfaces. J Stem Cell Res Ther 4: 233. doi:10.4172/2157-7633.1000233

Page 10 of 10

26. Son B, Kozaki K, lijima K, Eto M, Kojima T, et al. (2006) Statins protect human aortic smooth uscle cells from inorganic phosphate induces calcification by restoring Gas6-Axl survival pathway. Circ Res 98: 1024-1031. [PubMed]

27. Lee M, Lowe G, Strong D, Wergedal J, Glackin C (1999) TWIST, a basic helixloop-helc transcription factor can regulate the human osteogenic lienage. J Biol Chem 75: 566-577. [PubMed]
28. Colter D, Sekiya I, Prockop D (2001) Rapid expansion of recycling stem cells in cultures of plastic-adherent cells from human bone marrow. Proc Natl Acad Sci USA 98: 7841-7845. [PubMed]

29. Sekiya I, Larson B, Smith J, Pochampally R, Cui J, et al. (2002) Expansion of human adult stem cells from bone marrow stroma: conditions that maximise yields of early progenitors and evaluate their quality. Stem Cells 20: 530-541. 